\title{
Design and qualification of a supersonic wind tunnel for induced boundary layer transition research
}

\author{
H. Bottini, G. Paniagua, P. Schreivogel, A. Sonda \\ Turbomachinery and Propulsion Department \\ von Karman Institute for Fluid Dynamics \\ Chaussée de Waterloo 72, 1640, Rhode-Saint-Genèse, Belgium \\ henny.bottini@email.it \\ gpaniagua@me.com \\ and \\ S. de las Heras \\ Department of Fluid Mechanics \\ Polytechnic University of Catalonia, C. Colom 11, 08222 Terrassa, Spain
}

\begin{abstract}
This paper presents the design and the results of the qualification test campaign of a multiple-Mach-number supersonic wind tunnel designed for induced boundary-layer transition. Its characteristics, function, and instrumentation are described. The range of Mach numbers successfully span is presented along with the measured intensities of freestream fluctuations. All the measurement techniques implemented in the test campaigns after the qualification are introduced, and some results shown and commented to highlight their potentialities.
\end{abstract}

Keywords: supersonic flow, wind tunnel qualification, freestream fluctuations, boundary layer transition, measurement techniques

\section{Introduction}

The prediction and control of turbulence onset within boundary layers are vital in external and internal Aerodynamics. ${ }^{1,2}$ Numerical studies are fruitfully used in both fields, but experiments cannot be dispensed of, especially as the Mach number increases. ${ }^{3,4}$ Experiments in natural boundary layer transition require a facility that interferes as less as possible with the transition process. At the supersonic Mach numbers, for instance, the facility must not produce strong pressure fluctuations, namely, their RMS should be less than about $1 \%$ of $p_{\infty},{ }^{5}$ and the velocity fluctuations should be bounded. ${ }^{6}$ If not so, the influence of $p^{\prime}$ and $u^{\prime}$ on the transition process would hinder the extrapolation of the experimental results to real-flight conditions. ${ }^{7}$ It has been proven ${ }^{7}$ that the main cause of pressure fluctuations inside the test section of a supersonic wind tunnel is the turbulent boundary layer on the test section walls, which radiates pressure disturbances onto the test article. Therefore, the solution for having meaningful transition experiments is to keep the boundary layer laminar on those walls. That is, to have a so called "quiet supersonic wind tunnel". More than one feature must be implemented to reach this kind of quietness, and usually they require adjustment, corrections, or improvements and modifications before they become plainly operative. ${ }^{8,9}$ On the other hand, the quietness requirement is less stringent for experiments in induced boundary layer transition. These are when the turbulent state is forced to set on by an external agent, typically roughness elements located on the wall where the boundary layer develops. In fact, the disturbances introduced by the roughness are often as high as to outplay the disturbances due to the facility environment. ${ }^{10}$

In the present paper the characteristics and properties of a supersonic multiple-Mach-number wind tunnel for transition experiments are described. Results from its qualification test-campaign illustrates the breadth of the achievable Mach range, and the performance of its quietness features. Finally, an overview is given of the measurement techniques successfully used in the facility for induced boundary-layer transition experiments and skin friction measurements. 


\section{Wind tunnel characteristics}

The supersonic wind tunnel was realized by modifying a compression-tube facility originally intended for turbomachinery research. Richards ${ }^{11}$ adopted the principle of the Isentropic Light Piston Compression Tube developed at Oxford University by Schultz et al. ${ }^{12}$ Air is compressed in a tube by a free piston, and thereby heated up, and subsequently released into the test section through a fast acting slide valve. The main modifications are the addition of the convergent-divergent nozzle to generate the supersonic flow, and the removal of the piston used to compress the air in the compression tube. To these modifications add the evacuation into atmosphere instead of into a vacuum tank, and the use of this vacuum tank as part of the boundary-layer aspiration system. The air enters the nozzle convergent from the compression tube by the opening of a slide/shutter valve and is finally vented out to atmosphere through a silencer. Figure 1 shows the wind tunnel general arrangement (top) and the test section with the convergent-divergent nozzle (bottom right).

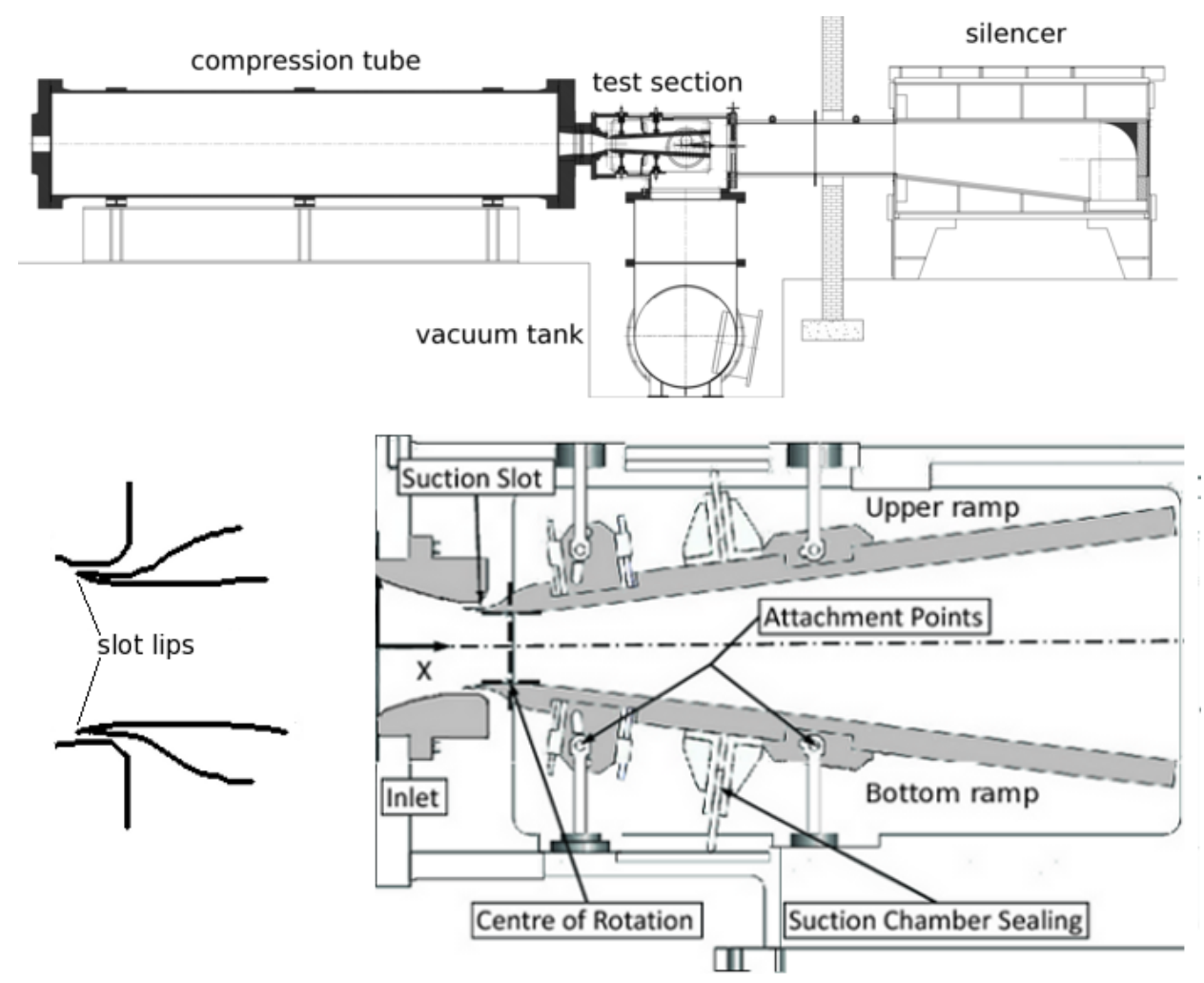

Figure 1: Top: General view of the facility Bottom: The test section with the mechanical arrangement of its movable ramps, and the detail of the bleed slots

The movable ramps constitute the divergent part of the supersonic nozzle. Changing their angle allows to control the degree of the supersonic expansion, hence the Mach number values through the divergent. Since this angle change is made operating on two screws per ramp (Figure 1 bottom right) that allow vertical movements in two distinct positions, the throat area, thus the mass flow, can be kept constant as the Mach number changes.

To avoid strong pressure disturbances in the test section the boundary layer must be laminar on those parts of the wind tunnel from where it could radiate noise onto the test article. The boundary layer along the ramps, then, is kept laminar by using suction slots just upstream of the nozzle throat, and by accurate wall polishing. These are the two main solutions currently used in operating quiet wind tunnels. ${ }^{13}$

\subsection{The suction slots and the aspiration system}

Suction slots (Fig. 1 bottom) are openings upstream of the throat of the wind tunnel that ingest the boundary layer developed along the walls of the convergent. In this way, a fresh boundary layer emerges from the suction slot 
lips into the supersonic test section. This boundary layer then is much less contaminated by disturbances than the ingested one. Therefore, it is much more prone to stay laminar throughout the test section. ${ }^{13}$ In the present design it has been possible to apply a suction slot only to two sides of the wind tunnel throat: the upper and the lower, that is the two movable ramps.

The boundary layer ingestion in the present arrangement is activated by an aspiration system downstream of the suction slots. This system is comprised of a large vacuum tank beneath the test section of the wind tunnel (Fig. 1 top), connected to the suction slots through a total of four tubes. The tank is complemented by the void part between ramps and the casing downstream of the slots throat (Fig. 1 bottom right). When the valves of the tubes open, the vacuum tank starts aspirating air from the slots at a flow rate that chokes the slots throat and make the flow highly supersonic downstream of them (Fig. 2 top).

To avoid recirculation bubbles along the inner walls, a special contour of the slot lip must be designed. A recirculation bubble can be generated by two different suction regimes, strong and weak, and both of them have to be dealt with to avoid disturbances within the boundary layer (Fig. 2 bottom row). ${ }^{13}$

In the case of strong suction, a stagnation point will occur on the side of the suction-slot lip toward the wind tunnel center-line (inner wall). Thus the subsonic boundary layer flow to be ingested by the slot experiences an acceleration around the lip just followed by a deceleration flowing downstream along the straight surface of the outer wall. In the case of weak suction, on the other hand, the stagnation point moves to the outer surface of the lip, leading to a recirculation bubble on the inner wall. Both of these configurations can cause dangerous perturbations in the boundary layer flow heading to the divergent. The configuration due to the weak suction may be particularly harmful because it creates noise directly in the downstream flow increasing the risk of early transition of the boundary layer on the tunnel walls. The case of strong suction could also cause perturbations in the main flow, if the mass flow through the slot becomes unsteady and produces oscillations on the stagnation point on the suction lip.

To avoid both dangerous regimes, an adapted suction regime has to be achieved by designing the suction lips with a specific shape. ${ }^{13}$ In fact, a perfectly round lip (as in the sketches on the bottom of Fig. 2, the most straightforward shape, and historically one of the first configurations used) was soon found too prone to form highly unsteady recirculation bubbles, and new contours were investigated. The most promising resulted the modified super ellipse contour described by the following equation

$$
\begin{array}{r}
\left(\frac{y}{b}\right)^{2}+\left(\frac{a-x}{a}\right)^{m}=1 \\
m=2+\left(\frac{x}{a}\right)^{2}
\end{array}
$$

where $a$ and $b$ are the major and minor axes of the ellipse. With this profile, the curvature goes continuously to zero as $x \rightarrow a .^{14}$ This contour has been selected for the suctions lips of the wind tunnel here presented, and to verify its effectiveness CFD computations have been performed. They are presented in the following paragraph.

The verification of the correctness of the suction lip design required laminar computations to be performed, since this is the state of the boundary layer that the suction slots are designed to preserve. To perform such computations the commercial software $C F D++$ was selected. ${ }^{15}$ Considering the geometry of the whole wind tunnel, 2-D computations were set up. Measured quantities as total pressure, total temperature, wall temperature, and nozzle exit static pressure were used as boundary conditions for all these laminar computations. Along with the whole suction slot, the entire supersonic wind tunnel was resolved from the junction to the compression tube downstream to the main divergent exit (Fig. 2 top).

The computations were made at two Mach numbers, 1.6 and 2.3. Figure 3 shows the detail of the structured 850000 -element mesh in the central part of the wind tunnel with the suction slot evident upstream of the sonic throat. The insert in this figure zooms in on the mesh structure around the suction-slot lip.

The middle row in Fig. 2 shows the results of the computations performed to verify the lip design, for the widest possible ramp angle, $4.7 \mathrm{deg}$., corresponding to Mach 2.3, and for the smallest ramp angle qualified, 1.2 deg., corresponding to Mach 1.6. Each color map shows the flow streamlines and the field of the velocity axial component around the modified super-elliptical tip.

The streamlines pattern for both angles shows that no laminar recirculation bubble is caused by the elliptical suction tip; neither on the immediate outer wall nor on the inner wall. It also explains why negative values of the axial component of the flow velocity appear in the field: the flow moves up from the stagnation point around 


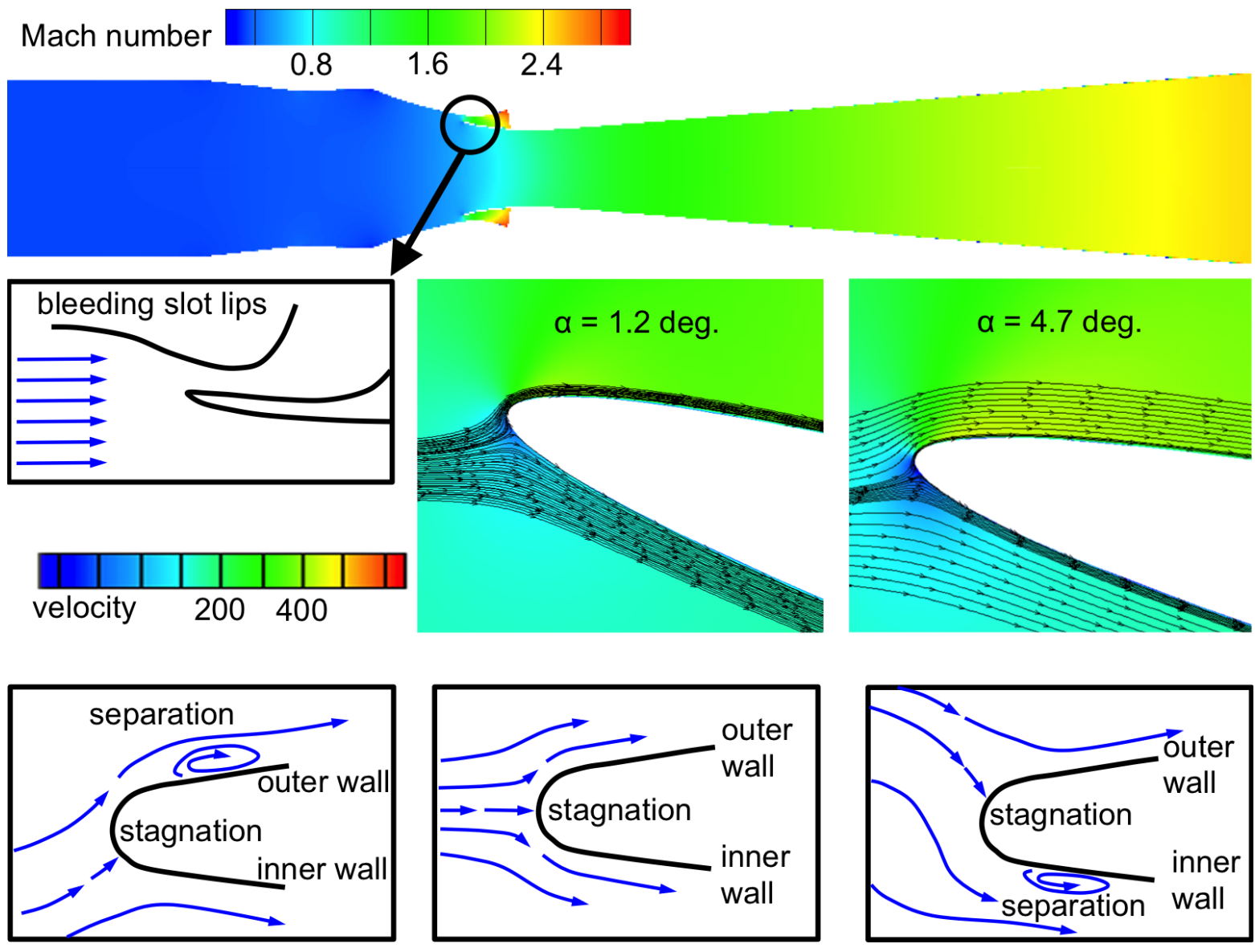

Figure 2: Top row: typical flows around the lip of a suction slot; bottom row: streamlines and velocity contours around the lip tip for $\alpha=1.2 \mathrm{deg}$. (left) and $\alpha=4.7 \mathrm{deg}$.(right)

the tip, and in so doing moves back a short axial distance. In conclusion, the CFD computations show that no recirculation bubble is present around the slot tips for the largest and smallest divergent angle qualified, thus for the two most extreme tip positions possible.

It must be noted that recirculation bubbles are usually formed because of strong adverse pressure gradient in the boundary layer. In the present situation these adverse pressure gradient can come only from the angle of attack of the tip respect to the flow. This in turn is determined only by the ramp angle. Thus, since no recirculation bubble appears for the smallest and the largest ramp angles possible, one can plausibly conclude that it will not appear neither for all the intermediate ramp angles, and that the tip design is finally effective for all the Mach numbers possible by the facility.

\subsection{Surface treatment of the nozzle walls}

Even the most sophisticated and performing boundary layer removal technique can result useless if not complemented by very highly polished nozzle surfaces. In fact tests showed that the wall and freestream pressure fluctuations were found to scale with the mean wall shear for all Mach numbers. ${ }^{16}$ Refining the smoothness of the nozzle from a RMS of 2-10 $\mu \mathrm{in}$. to a RMS of 1-3 $\mu \mathrm{in}$. improved the Reynolds number at which the NASALangley Mach-3.5 tunnel is quiet by a factor of two. Therefore, high aerodynamic smoothness is deemed important, especially for the throat surface, and has been implemented throughout the walls of the present wind tunnel.

The "aerodynamic smoothness" of a surface can be judged taking as a reference the thickness of the laminar sub-layer of a hypothetical turbulent boundary layer at the location of interest. (The hypothetical turbulent boundary layer has to be compatible with the properties of the flow under exam.) Then, a surface can be consid- 


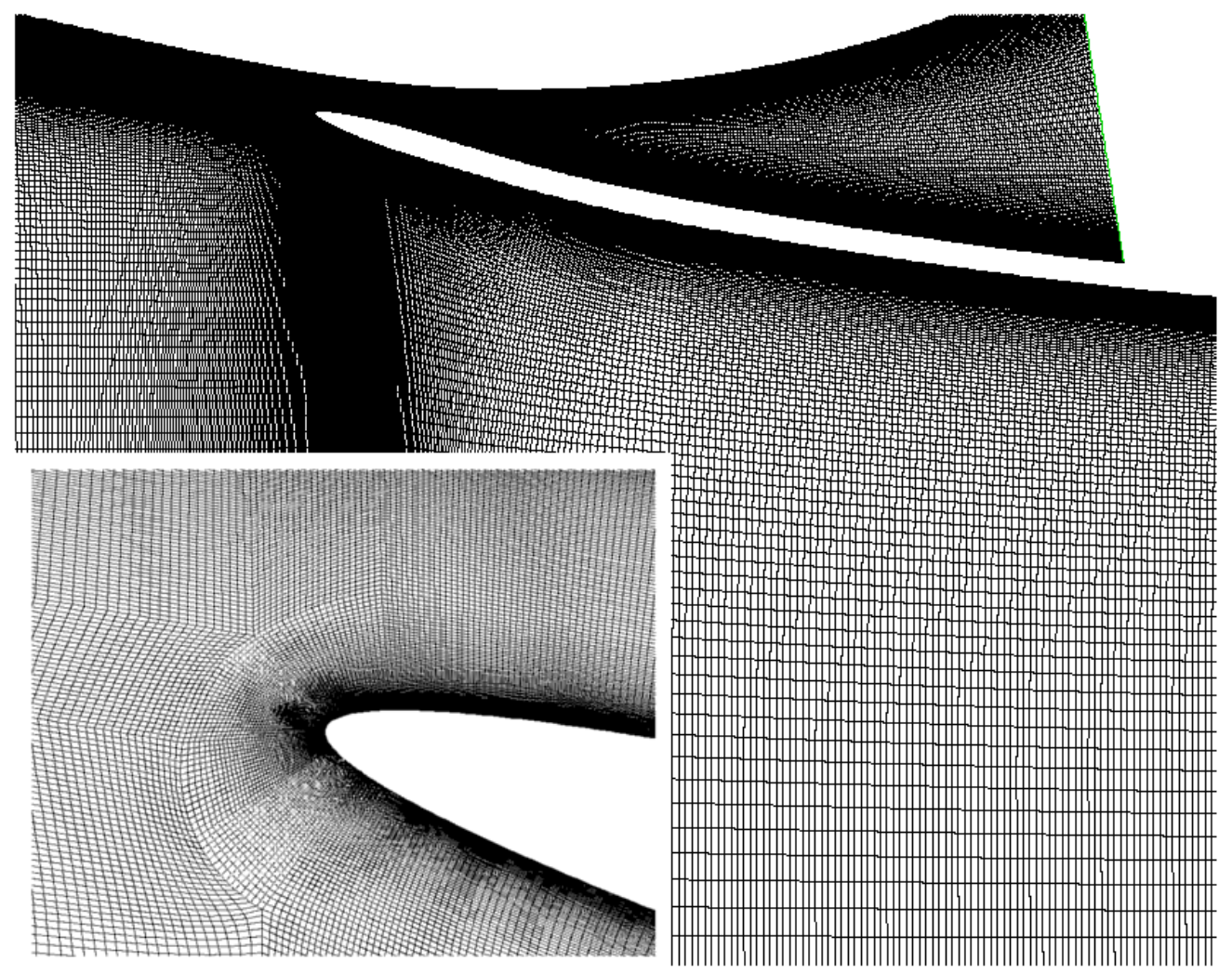

Figure 3: The structured mesh around the central part of the wind tunnel featuring the suction slot, and detail of the structured mesh around the suction-slot lip (divergent angle of $4.7 \mathrm{deg}$.)

ered smooth if the RMS value of its roughness height is less than the thickness of the laminar sub-layer of the hypothetical turbulent boundary layer. ${ }^{17}$

Usually ${ }^{18}$ the thickness of the laminar sub-layer is $y^{+}=5-6$ with

$$
\begin{aligned}
y^{+} & =\frac{y \cdot u_{\tau}}{\nu} \\
u_{\tau} & =\sqrt{\frac{\tau_{w}}{\rho}} \\
\tau_{w} & =\frac{\rho_{\infty} u_{\infty}^{2}}{2} C_{f}
\end{aligned}
$$

and the approximate maximum value for the $C_{f}$ to be expected for $M_{\infty} \in[1 \div 3]$ can be evaluated as $5 \cdot 10^{-3}$, taking into account the expected total temperature, thus the expected Reynolds number. This corresponds to a height of the laminar sub-layer in the range $6-11 \mu \mathrm{m}$, and this range was taken as reference for the wall polishing.

Both ramps, the convergent walls, and the divergent lateral walls have been mirror-polished, and their degree of smoothness was measured. These measurements were taken on one of the ramps by a roughness-meter Mitutoyo SJ-201P in five different locations across its entire width. More than one roughness measurement was taken as to check repeatability, and two quantities have been recorded: the RMS, $R_{q}$, and the average value, $R_{a}$, of the roughness height. The roughness standard selected was ISO. The measurements yielded an average value in the range $[0.06 \div 0.11] \mu \mathrm{m}$ and an RMS in the range $[0.08 \div 0.14] \mu \mathrm{m}$, i.e. two orders of magnitude less than the calculated laminar sub-layer thickness. These measurements lead to the conclusion that the ramps resulted smooth enough to prevent turbulence onset due to distributed roughness. Regarding the vertical side walls, no quantification of the roughness height has been possible for them. This is because the roughness-meter works 
only on horizontal surfaces, while these walls were kept vertical during the polishing. And their weight and integration in the facility prevented the necessary displacement and positioning for the measurement.

\section{Wind tunnel operation}

\subsection{Typical test cycle operation}

Initially the shutter valve is closed isolating the test section from the compression tube. Air is fed into this tube as to reach the total pressure required for the test. Total temperature increases in consequence of the compression process.

As the total pressure reaches the desired value the shutter is opened, and air starts its expansion through the convergent-divergent nozzle to the wanted test conditions. However, these conditions would not stay steady if only the air compressed at the beginning were used for the test. In fact the air-flow out of the compression tube would automatically decrease the pressure there, and reduce the total pressure of the test. This, in turn, would prevent any interval of time long enough to allow measurements at steady conditions. This situation is avoided by throttling a second air-feeding system that lets high-pressure air into the compression tube, and keeps the pressure inside it (thus the total pressure of the test) as constant as possible throughout the wind tunnel run.

The supersonic wind tunnel takes a finite time to start and establish the isentropic supersonic flow throughout the divergent. At the end of the run, then, air conditions come back to initial values also in a finite time. Figure 4 illustrates this process showing the signals of five pressure taps flush-mounted the end of the upper ramp (see Figure 1 bottom right). There appears how the flow starts at 0 seconds and how steady signals establish after about 0.2 seconds. They stay steady for about 0.3 seconds, then they start decreasing, and at about 0.65 seconds start gaining back the pre-test values. After 0.9 seconds the run is practically over.

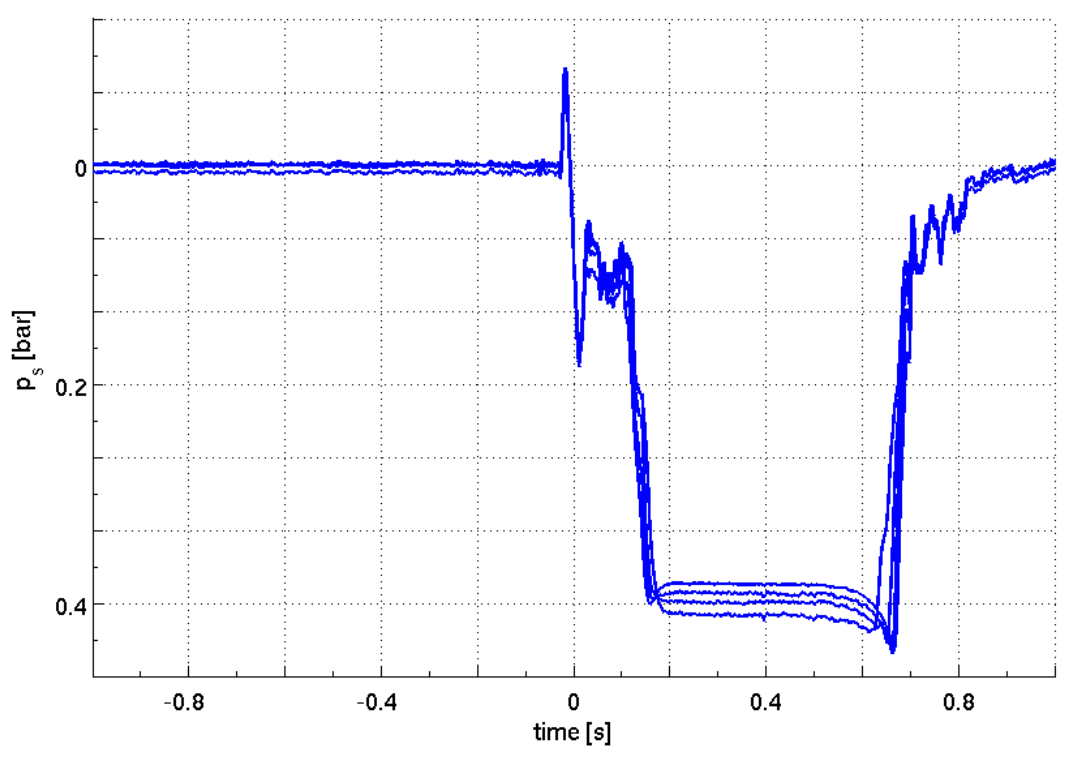

Figure 4: Static pressure time evolution during a wind tunnel run

The valves of the aspiration system that activates the suction slots open 0.1 seconds before the shutter, so that the boundary layer removal is already operative before the supersonic test conditions are reached.

\subsection{Parameters regulation}

The unit Reynolds number of each test depends on the setting of the total pressure $\left(p_{0}\right)$ and total temperature $\left(T_{0}\right)$. This dependency happens through the variations of freestream density and temperature. The supersonic Mach number, instead, once the throat is chocked, depends only on the divergent angle. Therefore, in principle, 

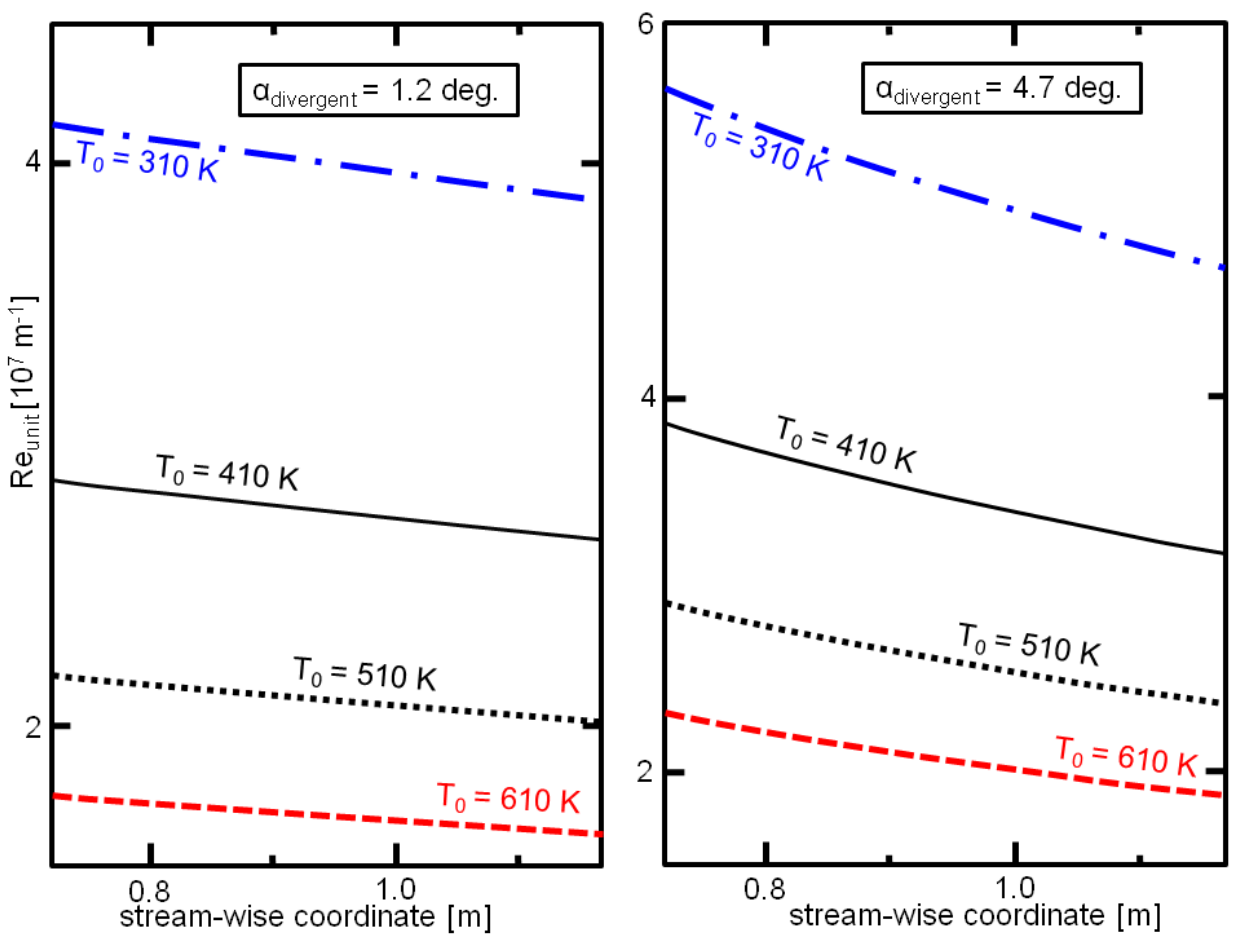

Figure 5: The unit Reynolds number evolution through the divergent at different total temperatures (left plot: $\alpha$ $=1.2$ deg., right plot: $\alpha=4.7$ deg.)

one can test for a given divergent angle in a range of Reynolds numbers just varying the values of total pressure and total temperature.

The total pressure value for each divergent angle has been assigned upon the successful starting of the wind tunnel. That is, the value of the total pressure for a test at a given divergent angle is the minimum value among those that succeeded in starting the wind tunnel during the qualification test campaign. The mechanical limits of the facility, then, set the highest safe total pressure at $5 \mathrm{bar}$. This value turned out to be the one needed to operate the wind tunnel at the widest divergent angle, that is, for the highest Mach number possible. This means that the total pressure change becomes more and more limited with the required Mach number. On the other hand, the total temperature can be varied more extensively acting on the initial pressure $\left(p_{i n}\right)$ of the compression process that builds up the test total pressure value. The facility, in fact, allows initial pressure values either lower or higher than ambient, thus the same compression process can yield different total temperatures as from

$$
\frac{T_{f}}{T_{i n}}=\left(\frac{p_{f}}{p_{i n}}\right) \frac{\gamma-1}{\gamma}
$$

Here $p_{f}=0.995 \cdot p_{0}, T_{i n}=T_{a m b}$ and $T_{f}=1.11 \cdot T_{0}$, with 0.995 and 1.11 empirical coefficients that account for the deviation from the ideal isentropic compression.

The two plots in Fig. 5 are for the smallest and largest ramp angles qualified, and show the unit Reynolds number evolution throughout the divergent for five $T_{0}$ values. The maximum total temperature is such that the lowest $p_{i n}$ is about $0.4 \mathrm{bar}$, an usual value for turbo-machinery testing, whilst the minimum is such that the lowest possible freestream temperature is always higher than $90 \mathrm{~K}$. Reynolds numbers are plotted against the axial direction spanning the length of the lower ramp section that can be instrumented $([720 \div 1120] \mathrm{mm}$ ).

Both plots show that the unit Reynolds number decreases with total temperature and with the length flown. This is because at fixed total pressure, an increase of total temperature yields an increase of dynamic viscosity and a decrease of density, both leading to the decrease of the unit Reynolds number. The combination of these two effects evidently outplays the effect of the increase in flow velocity due to the increase of the speed of sound at a fixed Mach number. Then, as the flow expands through the divergent, at constant total temperature 
and pressure, density and viscosity decrease, and the Reynolds number also decreases because density changes are more important than viscosity changes. However, the streamwise decrement is not very large: $+19 \%$ at maximum, which happens for the widest divergent angle $(4.7 \mathrm{deg}$. $)$ and the highest total temperature $\left(T_{0}=\right.$ $610 \mathrm{~K})$. The minimum is $+6 \%$ for the narrowest angle $(1.2 \mathrm{deg}$. $)$ and the lowest total temperature $\left(T_{0}=\right.$ $210 \mathrm{~K}$ ). This is the difference in percentage between values of the unit Reynolds number at the beginning of the instrumented section and at its end.

Another parameter that can be varied is the test time. This can be estimated as $t_{\text {test }} \simeq \frac{m_{\text {tube }}}{\dot{m}^{*}}$, considering the mass-flow thorugh the nozzle throat in critical condition as ${ }^{19} \dot{m}^{*} \propto \rho_{0} A^{*} \sqrt{T_{0}}$, and putting $m_{\text {tube }}=\rho_{0} \cdot V_{\text {tube }}$ as the mass of air inside the compression tube ready to be blown through the nozzle. As a consequence, the test time depends inversely on the throat area as

$$
t_{\text {test }} \propto \frac{V_{\text {tube }}}{A^{*} \sqrt{T_{0}}}
$$

Thus, the test time decreases with the throat height for a given total temperature, and also decreases with total temperature for a given throat height.

\section{Wind tunnel qualification}

The wind tunnel qualification consisted firstly in proving the correctness of the wind tunnel starting, i.e. the presence of a shock-free supersonic expansion in the divergent. Secondly, it focused on measurement of the wind tunnel noise to assess the wind tunnel degree of quietness.

\subsection{Practical Mach range achievable}

The wind tunnel was designed to operate at different Mach numbers, therefore its starting was verified for a range of Mach numbers. The absence of the shock was verified by the use of fifteen pressure taps drilled on the ends of the two ramps that constitute the divergent of the nozzle (ten taps on the lower ramp and five on the upper ramp, Fig. 6). The evolution of the static pressure at the wall was compared with pressure and Mach number axial evolutions produced by quasi-1D calculations of a supersonic shock-free expansion. These calculations had as inputs the measured total quantities of the run. An example of comparison between the calculations and the measurements is illustrated by the plots in Fig. 7 for the static pressure.

The measured pressure evolution along the divergent matches very satisfactorily the theoretical evolution in the top plot. This means that no shock wave is present in the divergent, that is the wind tunnel is correctly started for the total pressure value selected for the test. For the sake of comparison, the bottom plot shows the static pressure measurements for a case when the wind tunnel failed to start. Between 800 and about $900 \mathrm{~mm}$, measurements are fairly in agreement with the theoretical trend, as in the top plot, but behind $900 \mathrm{~mm}$ they rapidly diverge to a higher value that seems also to increase slightly and linearly after $100 \mathrm{~mm}$. This first rapid increase in pressure is due to the shock wave sitting within the divergent. This shock forces the flow to adapt to the nozzle back pressure, that is, the ambient pressure. The shock formed because the ratio between the total pressure of the test and the nozzle back pressure was not high enough as for the test represented by the top plot. Shock-free supersonic expansion was verified for the Mach numbers presented by Table 1. Here are also presented the corresponding unit Reynolds numbers, and total pressures for each Mach number.

\begin{tabular}{ccc}
$\begin{array}{c}\text { MACH NUMBER } \\
{[-]}\end{array}$ & $\begin{array}{c}\text { UNIT Re } \\
{\left[10^{7} \mathrm{~m}^{-1}\right]}\end{array}$ & $\begin{array}{c}\mathrm{p}_{0} \\
{[\mathrm{bar}]}\end{array}$ \\
\hline \hline 1.6 & 4.1 & 3 \\
1.7 & 3.8 & 3 \\
1.9 & 5 & 4.2 \\
2.3 & 5.4 & 5 \\
\hline
\end{tabular}

Table 1: Mach number range, unit Reynolds numbers, and corresponding total pressure at which the multipleMach-number wind tunnel was succesfully started 


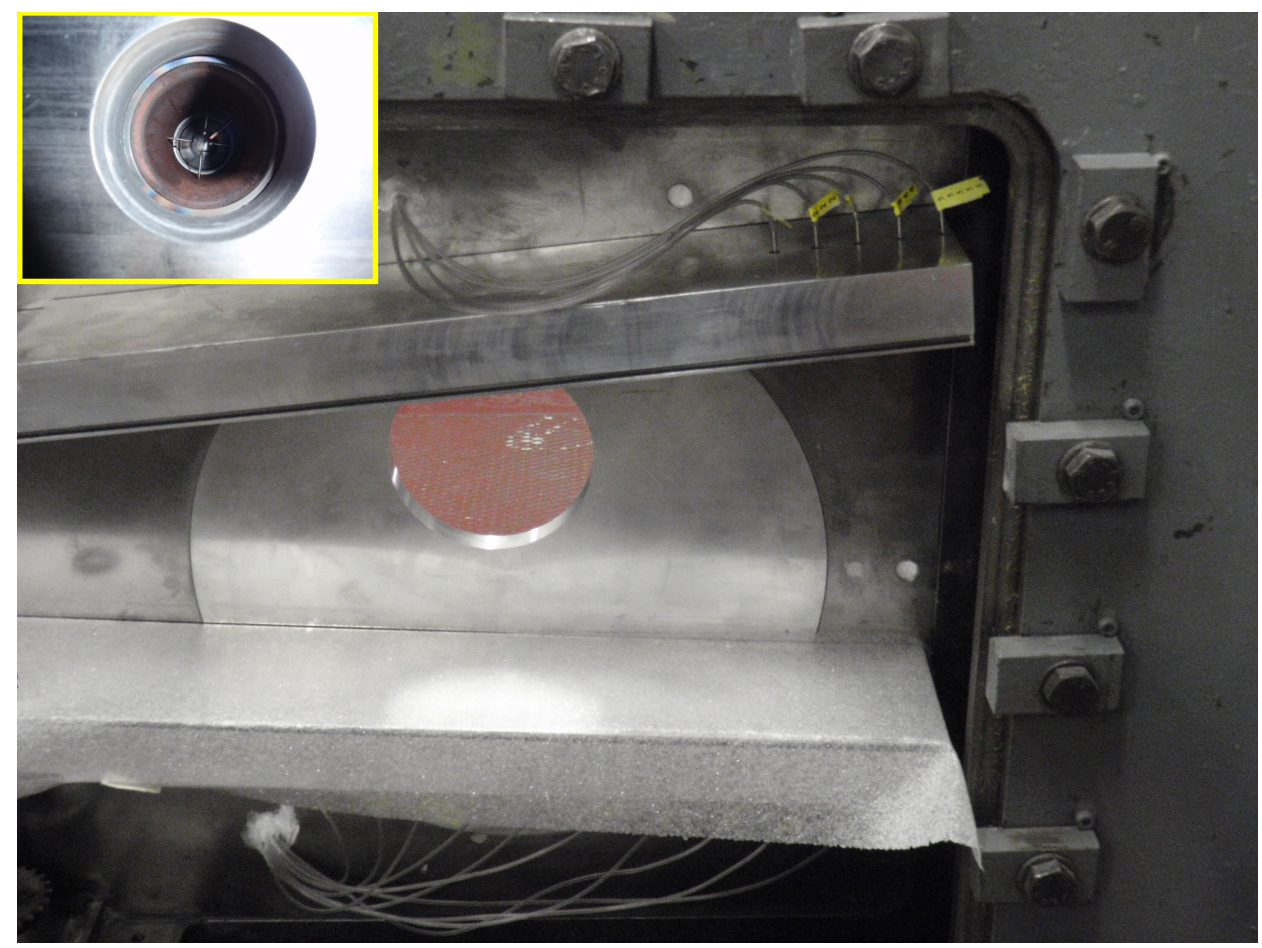

Figure 6: The two ramps instrumented for the qualification test campaign: the upper ramp features five pressure taps, the lower ramp ten (insert: the four static pressure L-shaped taps and the thermocouple inside one of the four aspiration system tubes)

Note that, since the tests are made in the divergent of the supersonic wind tunnel, an axial location had to be selected to which refer the test Mach number. This was $80 \mathrm{~cm}$ from the ramp (suction slot) tip, corresponding more or less to the middle of the instrumented part of the lower ramp.

\subsubsection{Evolution of the static pressure in the normal direction}

The correctness of the wind tunnel operations was judged upon the axial pressure evolution measured by sensors flush mounted on the divergent wall, that is, away from the centerline. Quasi-one-dimensional supersonic flow theory states that the static pressure should not change appreciably across a divergent section whose angle is small. In the present case the largest angle possible is $4.7 \mathrm{deg}$., hence the pressure taps on the divergent ramps should give sufficiently reliable measurements of the centerline values. Nonetheless, numerical simulations of the flow throughout the entire wind tunnel were performed to support the experimental campaigns, and their results were used to check also this aspect. Figure 8 shows the trends of the static pressure with the distance from the centerline at three different positions in the divergent, and for a freestream Mach number of 1.7.

The maximum absolute difference between the centerline and the wall values is about $0.45 \%$ of the centerline value $(\sim 200 \mathrm{~Pa}$ ) at the location marked $0.95 \mathrm{~cm}$. It is thus evident how the pressure variations normal to the centerline are very feeble and do not endanger the conclusions on the flow drawn by the wall measurements.

\subsection{Assessment of wind-tunnel noise by hot-wire measurements}

Quiet wind tunnels must generate very low disturbances, and these are mainly due to the turbulent boundary layer along the wind tunnel walls. However, also freestream fluctuations play a role at supersonic Mach numbers ${ }^{7}$ and they are generated in the most upstream parts of the facility. Hence, a complete assessment of wind tunnel quietness should comprise freestream turbulence quantification as well.

The freestream turbulence measurements consisted in the measurements of the mass-flow fluctuations, and were made with a double hot-wire probe mounted on a boom on the axis of the test section (see Fig. 9). The hotwires were of the constant-temperature type, platinum-coated, $3-m m$-long, and had a diameter of $9 \mu m$. Only 


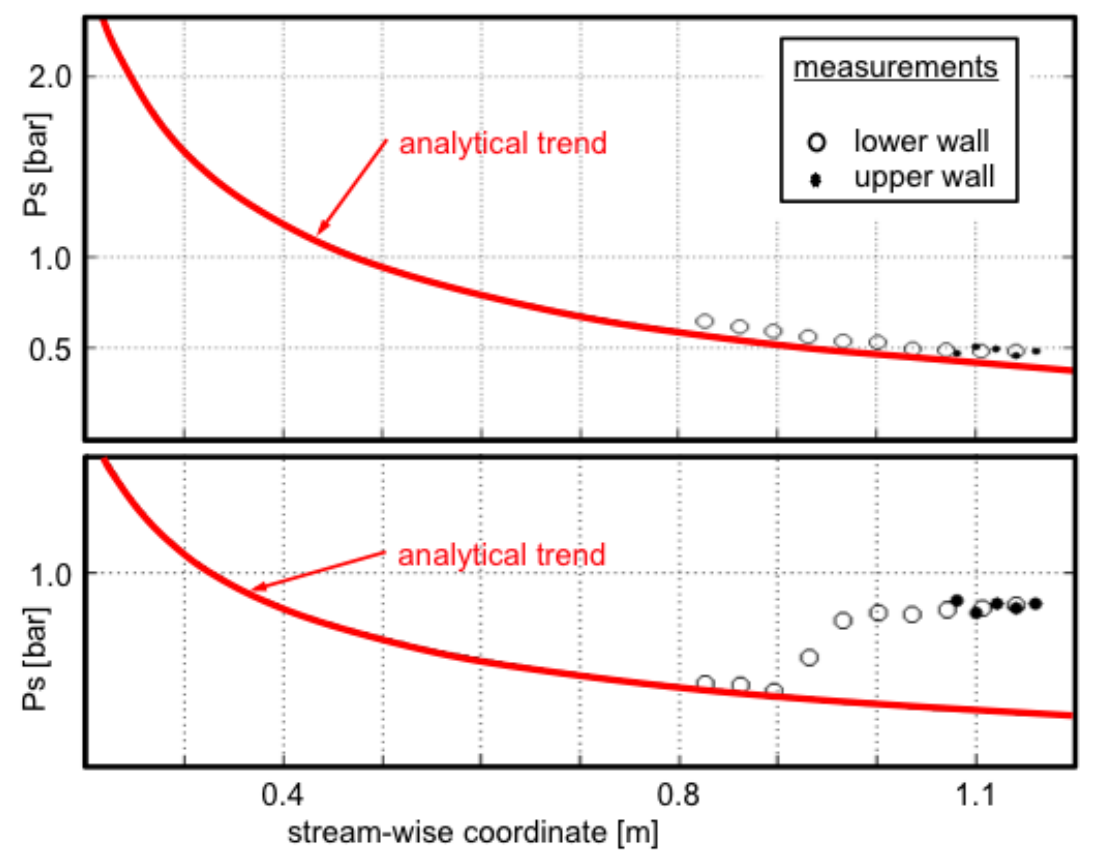

Figure 7: Top: typical static pressure axial evolution throughout the whole nozzle divergent $\left(p_{0}=4.2\right.$ bar $)$ Bottom: static pressure axial evolution in case of un-started wind tunnel $\left(p_{0}=3 \mathrm{bar}\right)$

the wire with the highest over-heating ratio $\left(R_{w} / R_{a}=1.6\right)$ was capable of yielding a good signal-to-noise ratio, thus only its measurements were taken into account. The hot-wire electronics allowed a maximum frequency resolution of $20 \mathrm{kHz}$.

The hot-wire calibration was made in situ, i.e. at the same time as the measurements. This happened as follows. The mean flow quantities in each test were calculated from $p_{0}, p$ and $T_{0}$ measurements, and time intervals in which they were mostly constant were singled out of the entire test duration. Then, the mean values of $\rho U$ were plotted against the corresponding hot-wire voltage outputs so to have a calibration curve of the type

$$
E^{2}=A+B(\rho U)^{0.5}
$$

for each test. From this calibration function, the inverse function $(\rho U)=f(E)$ was obtained and applied to the time-dependent hot-wire output to yield the values of the mass-flow fluctuations $\rho U^{\prime}$.

As the upper limit of the fluctuations frequency range was set at $20 \mathrm{kHz}$ by the electronics, for the lower limit some considerations had to be done. It has been soon evident that the entire facility vibrated during each test, and so did the boom hosting the hot-wire. These low-frequency mechanical vibrations were recorded by the hot-wire as flow fluctuations, and thus had to be removed from the hot-wire signals during the post-processing. An estimation of the range of these vibrations has been possible thanks to some previous tests made with a flat plate mounted as a cantilever in the test section and equipped with an accelerometer (Fig. 10 left top and bottom). This accelerometer (ENDEVCO 2250AM1-10) recorded the vertical components of the plate vibrations. Even if the mechanical system composed by the plate and its supporting beams differed from that comprised of the boom and its support (the attachment to the wind tunnel was the same, instead), we considered the accelerometer data still as a good estimation of the mechanical vibrations suffered by the hot-wire. The frequency spectrum of the plate mechanical vibrations is reported in theright part of Fig. 10. There is shown how the strongest vibrations occur for a frequency less than $700 \mathrm{~Hz}$, a value that, hence, has been used as the lower limit for the frequency range of the mass-flow fluctuations.

In conclusion, the intensities of the freestream mass-flow fluctuations measured in the frequency range $[700 \div$ 20000] $\mathrm{Hz}$ are reported in Table 2 for two different Mach numbers. These Intensities are expressed as the ratio between the RMS and the average value. 


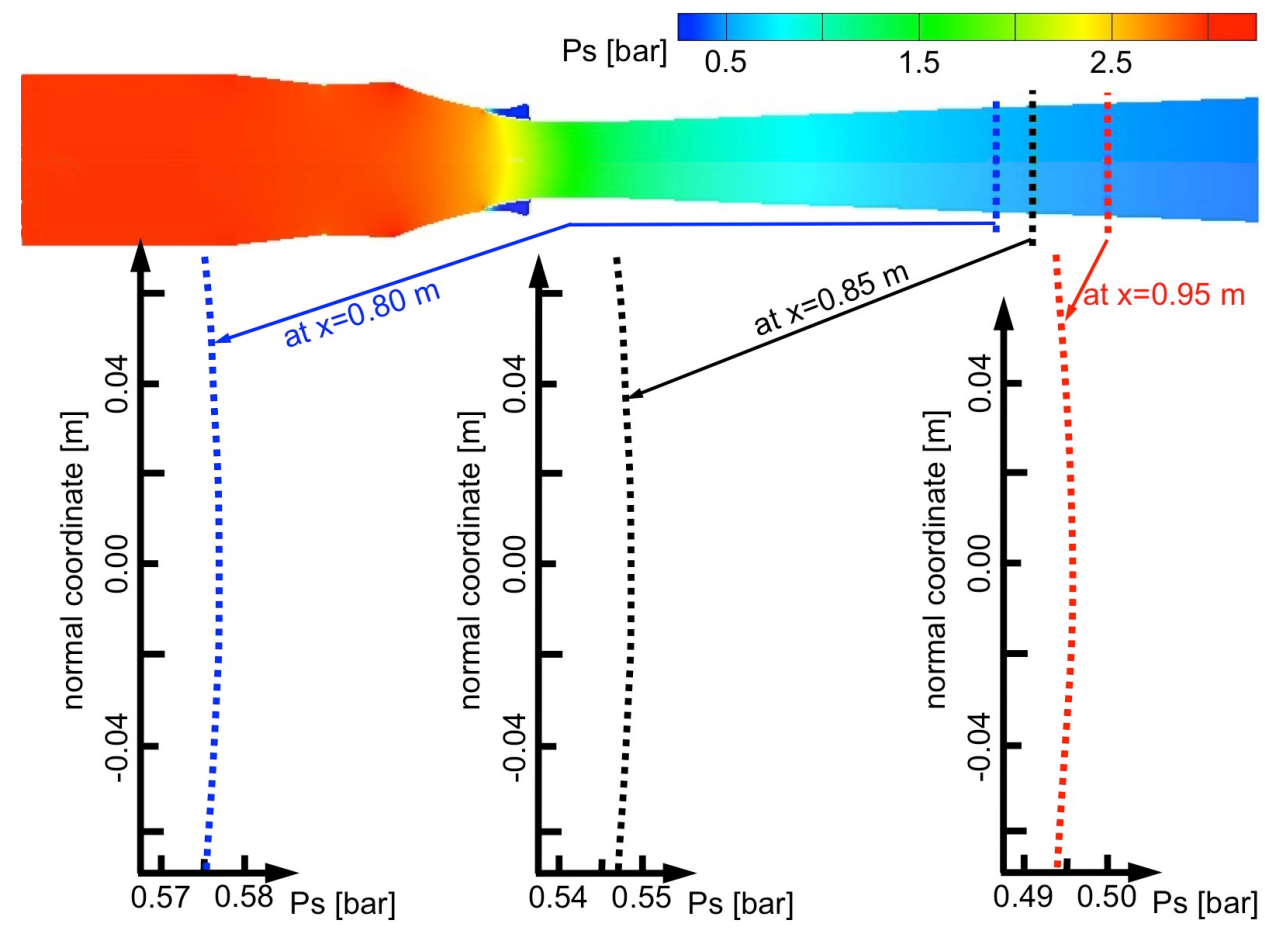

Figure 8: Static pressure evolution normal to the divergent centerline at three different positions
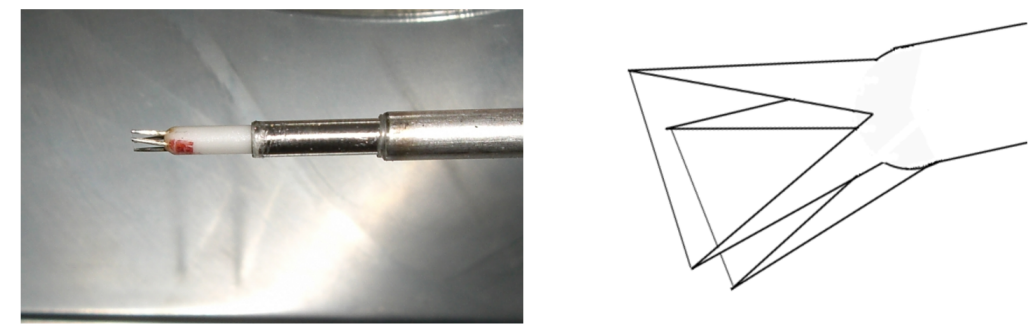

Figure 9: Left: the double hot-wire in the test section Right: sketch of the hot-wire head

These values are then included in Fig. 11 where they can be compared with data from other supersonic facilities. Here are shown (linked by lines) data measured in the 1960' in a JPL supersonic quiet wind tunnel, ${ }^{3}$ plus additional data about freestream mass-flow disturbances in the Russian ITAM wind tunnels T313 and T325. ${ }^{20}$ The JPL wind-tunnel featured a 1\%-turbulence-intensity settling chamber with four screens and one air filter; the ITAM T325 featured a settling chamber with honeycomb, ten screens, and a not-further-detailed noise-reduction system; finally, the T313 was reported as conventional.

Regarding the JPL data, the curve of interest for the comparison is that for the unit Reynolds number equal to $1.3 \cdot 10^{7} \mathrm{~m}^{-1}$ that features an interpolated value of about $0.1 \%$ for the Mach numbers tested in the present work. This means that the values measured in the facility are six to ten times those of this quiet wind tunnel, i.e. typical of non-quiet wind tunnels. This is confirmed by the value from the ITAM T313 (even if for a higher Mach number), and by the values of the ITAM T325 used at transonic conditions. In this latter case, the ITAM $\mathrm{T} 325$ is reported as noisier than as operated at supersonic conditions.

In this comparison, however, it must kept in mind that in the present wind tunnel there are none of the noise/turbulence-reduction devices that the JPL and ITAM facilities feature in their settling chambers. 

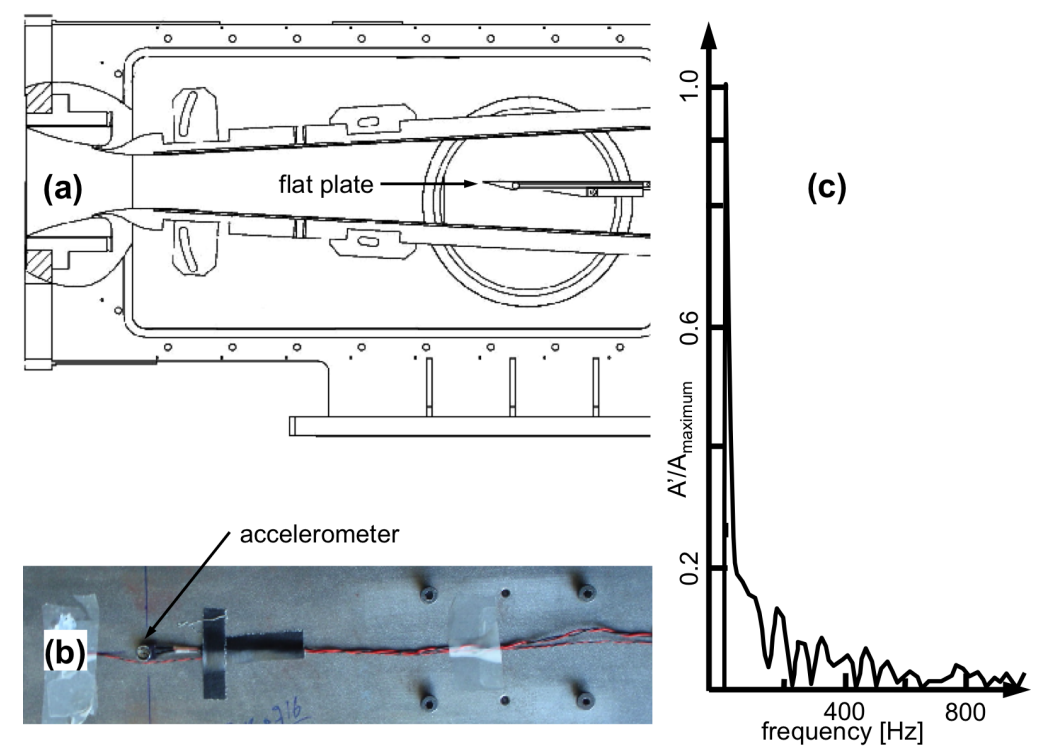

Figure 10: (a): the flat plate with the accelerometer in the test section (b) the accelerometer position beneath the plate (c): frequency spectrum of the flat-plate mechanical vibrations during a test

\begin{tabular}{ccc}
$\begin{array}{c}M_{\infty} \\
{[-]}\end{array}$ & $\begin{array}{c}\text { UNIT RE } \\
10^{7} m^{-1}\end{array}$ & $\begin{array}{c}\rho U^{\prime} \\
\frac{R M S}{\rho U}\end{array}$ \\
\hline \hline 1.7 & 3.8 & $0.63 \%$ \\
1.9 & 5 & $1.14 \%$ \\
\hline
\end{tabular}

Table 2: Freestream mass-flow fluctuations and the corresponding Mach and unit Reynolds numbers

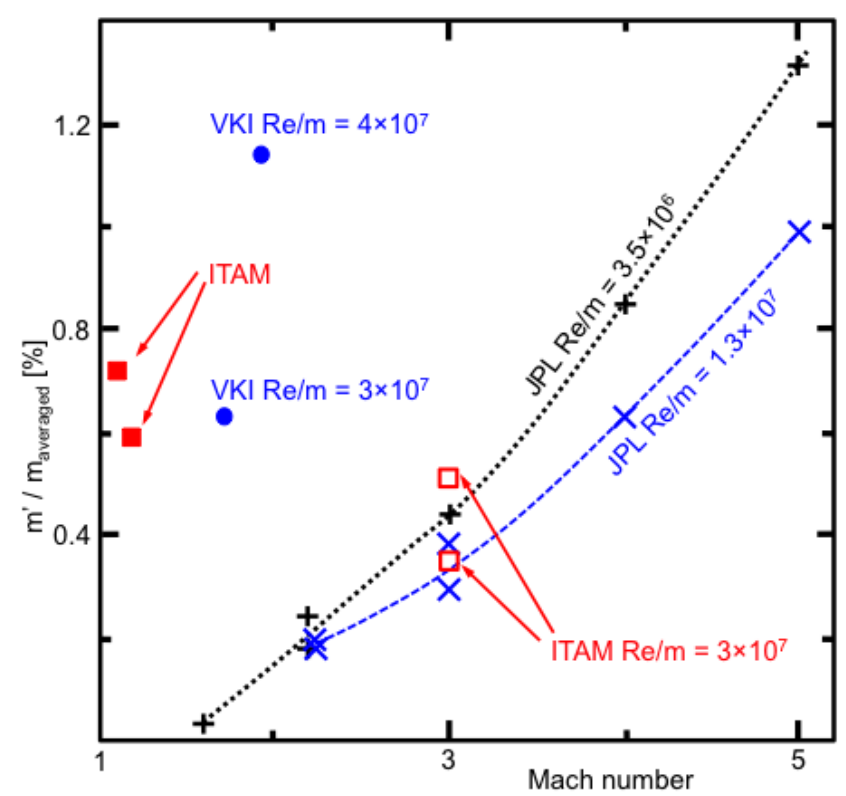

Figure 11: Variation of mass-flow fluctuations with freestream Mach number ${ }^{3}$ 


\section{Ad-hoc measurements techniques}

\subsection{Instrumentation to monitor the wind tunnel operation}

To command the correct function of the wind tunnel and to check the correct establishment of the supersonic flow, the compression tube, the boundary-layer injection system, and the wind tunnel divergent are permanently instrumented.

The total pressure in the compression tube is monitored by a Valydine DP15 variable-reluctance differential pressure transducer, and the total temperature by two type-K thermocouples. The pressure sensor is relied upon for opening the shutter as the wanted total pressure is reached, and thus for starting the flow and controlling the total pressure steadiness through the test time. Thermocouples are used to measure the total temperature, and to track its time evolution during the test. One thermocouple is located very near the total-pressure sensor, the other is flush-mounted on the front of the compression tube.

The four pipes that connect the vacuum tank to the suction slots are also instrumented to measure the mass flow. Each pipe is equipped with four total pressure piezoresistive probes, three static-pressure piezoresistive probes, and one type-K thermocouple. The four total pressure probes are arranged at the same depth inside the pipe and are spaced by 90 degrees to each other. This arrangement allows to have a fair representation of the inflow total pressure from the average of the probes measurements. The three static pressure probes are flush-mounted pressure taps located at the same distance from the pipe inlet as the total-pressure probes. The thermocouple, then, being exposed to the freestream, measures the total temperature of the flow. And it is located at the same depth and same distance from pipe inlet as the pressure probes (Figure 6 top left insert). Monitoring the mass flow of each pipe allows to control how the upper and the lower suction slots work, and whether they do work in the same correct way.

The same piezoresistive sensors used to instrument the aspiration system are used to sense the static pressure inside the nozzle divergent. They have a response time of $0.1 \mathrm{~ms}$. The upper ramp of the divergent is equipped with five pressure taps, each one connected to one piezoresistive sensor (see Figure 6). These taps are located close to the end of the ramp as to avoid acoustic radiation onto the instrumented part on the lower ramp.

Only for the qualification test campaign, also the lower ramp was instrumented with pressure taps, ten of them, that allowed to plot the static pressure evolution throughout most of the instrumented insert.

\subsection{Sensors for wall temperature measurements: thin-films}

Thin-films can instrument the lower ramp of the wind tunnel divergent and allow wall temperature measurements. The top part of Fig. 12 shows an arrangement of thirty thin-films used for a recent test campaign in the present wind tunnel. This campaign was aimed at tracking the boundary layer evolution downstream of a single roughness element at two supersonic Mach numbers.

The thin-film sensor (insert in the top picture of Fig. 12) is a thin serpentine of nickel fed with constant current by two copper wires. The thermal strain induced by the flow on the serpentine changes its electric resistance, thus the voltage across. Voltage changes, in turn, are recorded and, after the application of a calibration, yield the wall temperature measurement. The measurement provides the time evolution of average temperature and its fluctuations. The average temperature can be used as input to a $1 \mathrm{D}$ heat-conduction code to calculate the convection heat flux between the wall and the supersonic boundary layer. Then from the heat flux value the state of the boundary layer can be assessed. Moreover, the thin-film-instrumented plate can be heated by electric heaters, thus allowing measurements at different wall temperatures. These measurements, in turn, can be used to calculate the adiabatic wall temperature and, in conjunction with the heat flux measurements, the Stanton number, which can be used as a further gauge of the boundary layer state.

Thin-films feature as well a rather good frequency response to the thermal inputs, thus they are a valuable tool to investigate wall temperature fluctuations. This is not only useful to track turbulence onset along the instrumented insert, but also to characterize its frequency content when established. Thin-films own their good frequency response to the serpentine thinness $\left(10^{-1} \mu \mathrm{m}\right)$, that makes the characteristic time response to thermal inputs $\left(\tau_{c h a r}=\frac{t_{T F}^{2}}{\alpha}\right)$ of the order of $10^{-9} \mathrm{~s}$, and the corresponding frequency response $\left(f_{3 d B}=\frac{1}{2 \pi \tau_{c h a r}}\right)$ of the order of $10^{7} \mathrm{~Hz}$. However this is the ideal response of the sole sensor, which is limited by the practical frequency range of the electronic components of the measurement chain. Currently, the system of thin-films and relative electronics available for the facility has a frequency range upper limit of about $60 \mathrm{kHz}$. 

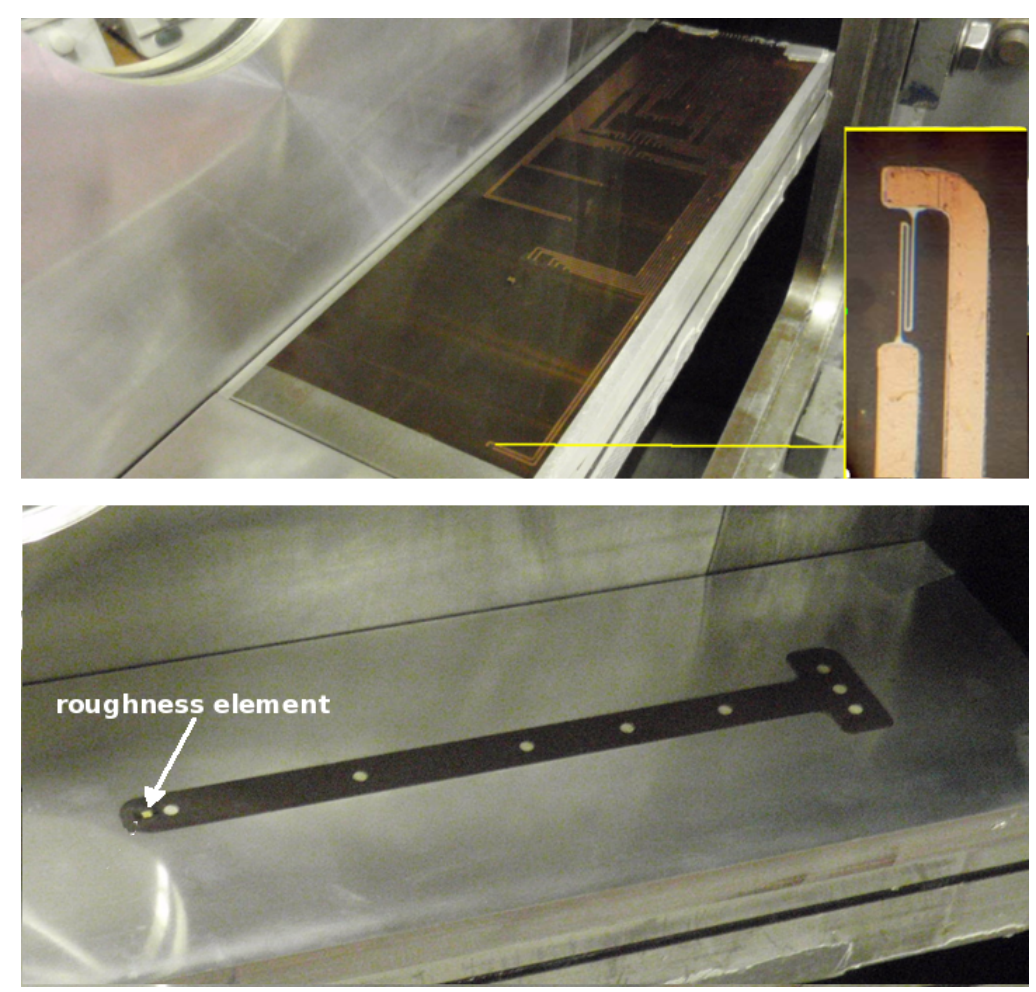

Figure 12: The thin-film (top) and the PCB (bottom) inserts embedded into the lower ramp of the supersonic wind tunnel (insert in the top picture: magnified view of a thin-film)

\subsection{Sensors for pressure fluctuations measurements: piezoelectric pressure transducers}

Piezoelectric pressure transducers (PCB) can instrument the lower ramp of the wind tunnel divergent to measure pressure fluctuations. Most often these fluctuations come directly from the boundary layer, but may also come from the freestream, if the boundary layer is fully laminar and still stable. In the former case PCBs well complement thin-films in the investigation of the boundary layer state, whilst in the latter case they can be used to assess freestream turbulence intensity.

In a recent test campaign eight of these sensors were flush mounted downstream of a roughness element to evaluate its effectiveness in triggering transition. The bottom picture in Fig. 12 shows their layout for the observation of streamwise and spanwise variation of pressure fluctuations. The rectangular roughness element is also shown upstream of the first sensor.

This type of transducers rely on the piezoelectric property of some solids to measure pressure fluctuations. There are two kinds of solids featuring this property: the ceramic and the single-crystal. Gallium phosphate, tourmaline, and the common quartz $\left(\mathrm{SiO}_{2}\right)$ belong to the first type, while sinterized materials, like pirovskite, belong to the second type. Piezoelectricity can be natural (e.g. quartz) or induced by electric polarization (e.g. pirovskite). The piezoelectric property consists in generating electricity under mechanical stress $(\pi \iota \varepsilon \zeta \omega=$ pressure $)$. The mechanical stress alters the spatial symmetry among the cations and the anions that form the crystal structure of the ceramic material and polarize it. ${ }^{21,22}$ In the case of sinterized materials, instead, mechanical stress changes the induced dipole moment of the molecules and creates a voltage difference. In both case, however, the electric effect of the mechanical stress is ephemeral and the produced charges eventually annihilate. This is why these sensors are best used to measure fluctuations rather than steady quantities.

Commonly, for pressure fluctuations measurements, the piezoelectric material is placed inside the sensor below and parallel to a flexible membrane. This membrane allows the compression stresses, caused by the pressure fluctuations on its outer side, to be felt by the piezoelectric material on its inner side. Since the piezoelectric material is very stiff, even a small stress yields a high electric output, so that this kind of sensors can have a remarkable dynamic amplitude range.

The piezoelectric pressure transducers used for the present facility (PCB 132A31) are of the ceramic type 
and have the piezoelectric material arranged for pressure fluctuations measurements. They feature a resonance frequency of $1 \mathrm{MHz}$, thus they allow measurements in a very broad frequency range in comparison with other pressure sensors. The current data-acquisition system allows to sample their signal at $1 \mathrm{MHz}$ and to low-pass filter it at $250 \mathrm{kHz}$. The electronics embedded in the sensor itself provides a high-pass filter at $11 \mathrm{kHz}$. The spectral analysis of the resulting high frequency signal is an useful tool to characterize the unsteadiness in the supersonic boundary layer.

\subsection{Technique for pressure field mapping: Pressure-Sensitive-Paint}

Pressure Sensitive Paint (PSP) is a measurement technique capable of mapping the pressure field generated on a surface by an air flow. It consists in laying on the surface a special paint containing luminescent molecules in an oxygen-permeable binder. ${ }^{23}$ During the measurement these molecules are excited by an external pulsing light source (e.g., lasers, LEDs, or a gas discharge lamp) and start emitting light at a wavelength larger than that of the excitation. The physical phenomenon that makes the pressure measurement possible is that the intensity and luminescent lifetime of the emitted light are sensitive to the ambient concentration of oxygen. This concentration is proportional to the oxygen partial pressure, which, in turn, is proportional to the local static pressure of the flow. Therefore, one can recover the local static pressure on each point of the PSP-coated surface by detecting the emitted light and by relating its intensity or lifetime to static pressure. Light detection is done by photomultiplier tubes or digital cameras, and the Sterner-Volmer equation, with a reference condition, is used to relate light emission to the flow static pressure:

$$
\frac{I_{r e f}}{I}=\frac{\tau_{r e f}}{\tau}=A(T)+B(T) \frac{p}{p_{r e f}}
$$

The intensity method is the most straightforward. A continuous illumination excites the paint, and a camera records the intensity of the paint emission. The camera has a filter to reject the light reflected and sense only the light emitted by the paint. This technique requires a normalization of each image with a wind-off reference in order to compensate variations in the local paint properties, e.g. thickness or luminophore concentration.

The lifetime technique is more complex and only recently has became attractive because of the improvements in camera sensitivity and dynamic range. In practice, lifetime measurements are (often) carried out using a pulsed illumination and a gated CCD camera that acquires at least two subsequent images, some (one) during and some (one) after the excitation. Each image is an integration of the paint emission intensity over the camera gate time. The intensity ratio computed from the image taken after and that taken during the excitation is proportional to the emission lifetime $(\tau)$, thus to the static pressure as from Eq. 9.

In the wind tunnel here presented both the intensity and lifetime techniques were investigated, but, for the sake of brevity, only results from the intensity method are shown. The reader can find the complete report of this investigation in reference, ${ }^{23}$ where the two methods have been used for the same test case and their results compared. The right side of Fig. 13 shows the map of the pressure field generated by the single roughness element glued on the bottom ramp of the supersonic wind tunnel as depicted on the left side of the same picture. The roughness dimensions for the tests were $h \times w \times l=5 \times 4 \times 4 \mathrm{~mm}^{3}$; the Mach number at the roughness position was 1.8. The map dimensions are $40 \times 32 \mathrm{~mm}^{2}$.

In this map the static pressure values are expressed relatively to the dynamic pressure. The image of the roughness looks very elongated because of the geometrical correction needed by the non-orthogonal angle of view of the cameras; the square drawn at the basis of this white zone signals the right position of the roughness respect to the pressure field.

\subsection{Technique for skin friction measurements}

Part of the development of a technique for the measurement of skin friction, based on the thin-oil-film method, ${ }^{24}$ has been carried out in the present wind tunnel for the low-supersonic flow regimes. The present facility gave the opportunity of testing its applicability in case of a favorable pressure gradient.

The thin-oil-film method relies on the principle that the rate at which oil thins along a surface flown by a fluid is function of the wall shear stress produced by the flow. This principle finds its mathematical expression in the thin-film theory that is used to quantify the skin friction from the measurements of the oil-film technique. ${ }^{25}$ The key relation is the one that links the height of the oil film, $h$, to the shear stress, $\tau_{w}$ 

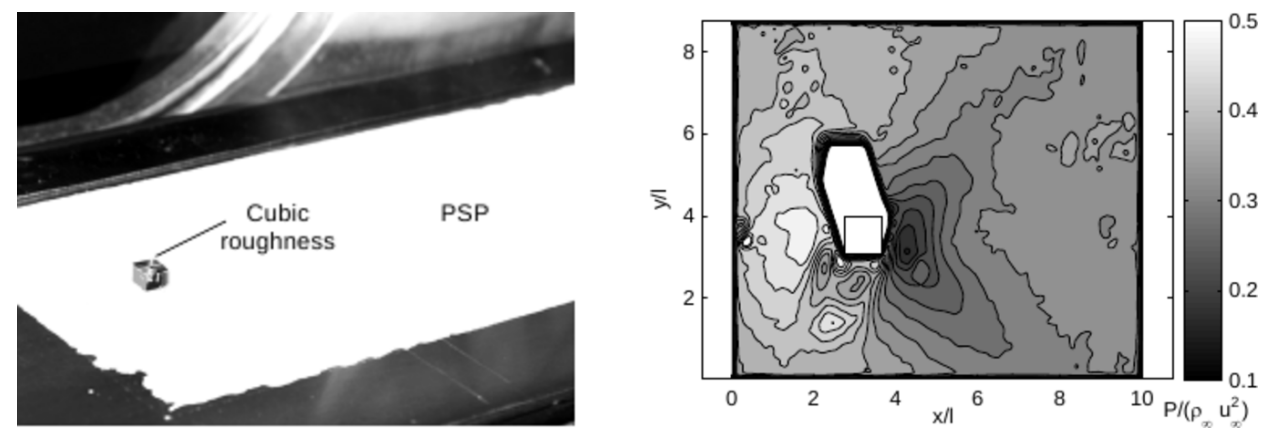

Figure 13: Left: Pressure Sensitive Paint applied around a cubic roughness on the bottom ramp of the wind tunnel divergent Right: PSP map of the static pressure field around a single roughness element in a $M_{\infty}=1.8$ flow, $l=4 \mathrm{~mm} \overline{\text { (intensity method) }}$

$$
h=\frac{\mu}{t \sqrt{\tau_{w}}} \int_{0}^{x} \frac{d x}{\sqrt{\tau_{w}}}
$$

This link is through viscosity, $\mu$, and time, $t$, and becomes simpler if no shear stress dependency on the axial coordinate $x$ is assumed

$$
h=\frac{\mu L}{t \tau_{w}}
$$

here $L$ is the axial distance moved by the oil film under the shear effect. It is thus possible to deduce $\tau_{w}$ from the slope of the oil surface because Eq. 11 holds near the leading edge of the moving film for any shear stress distribution. ${ }^{26}$ In practice the measurement technique consists in recording the deformation of the oil film by means of a high-speed camera, and post-processing the images as to have a measurement of the height of the film at the end of the test, $h$, and the distance flown by the oil, $L$. Equation 11 is then applied to these measurements, and the shear stress value obtained. To comply with the assumption about $x$-dependency, which Eq. 11 stems from, the oil is not applied uniformly across the ramp but in a variable number of dots arranged on one or two rows (Fig. 14(a)). Furthermore, in this way, the distribution of oil droplets allows a better compliance with the constant wall shear stress assumption also at the basis of Eq. 11.

The plot in Fig. 14(c) compares the experimental results of this technique with shear stress trends from CFD computations. These have been carried out in $C F D++$ for both the laminar and the turbulent cases, and for the latter the two-equation Realizable $k-\epsilon$ turbulence model was applied. Measurements were taken at two locations across the lower ramp of the wind tunnel divergent.

This plot shows a difference of about $+24 P a$ between the average measurements from across the first row (at $0.88 \mathrm{~cm}$ ) and the second row (at $0.91 \mathrm{~cm}$ ). Skin friction, in fact, decreases with the streamwise direction, as depicted by the CFD trends. However, the $+24 P a$ difference in the measurements is larger than the difference between the laminar or turbulent numerical values at 0.88 and $0.91 \mathrm{~cm}$. In the laminar case, in fact, this difference is about $1.5 \mathrm{~Pa}$, while in the turbulent case is about $8.5 \mathrm{~Pa}$. The comparison shows that they fall in between the two reference curves at both locations, slightly closer to the laminar curve than to the turbulent one, especially for the measurement from across the second row.

These differences among measurements and CFD trends may be due to the presence of the favorable pressure gradient or to the high distortion level of the images post-processed caused by the small optical access of the wind tunnel.

\section{Conclusions}

A supersonic wind tunnel equipped with peculiar features for the reduction of the facility-generated interferences on transition experiments has been qualified, and its performance assessed. It demonstrated the possibility of multiple Mach numbers in the range of $[1.6 \div 2.3]$ with corresponding unit Reynolds numbers in the range forty 

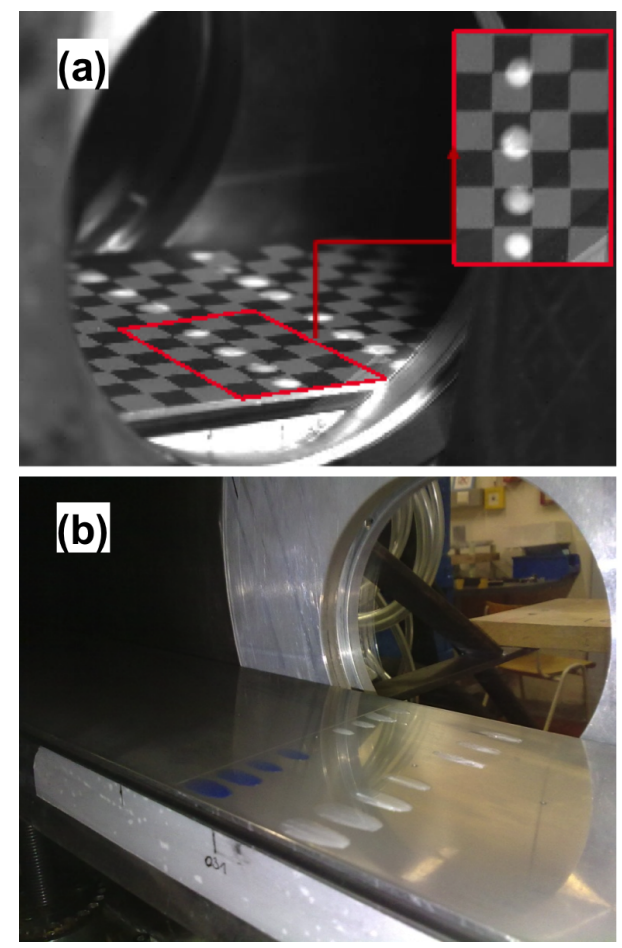

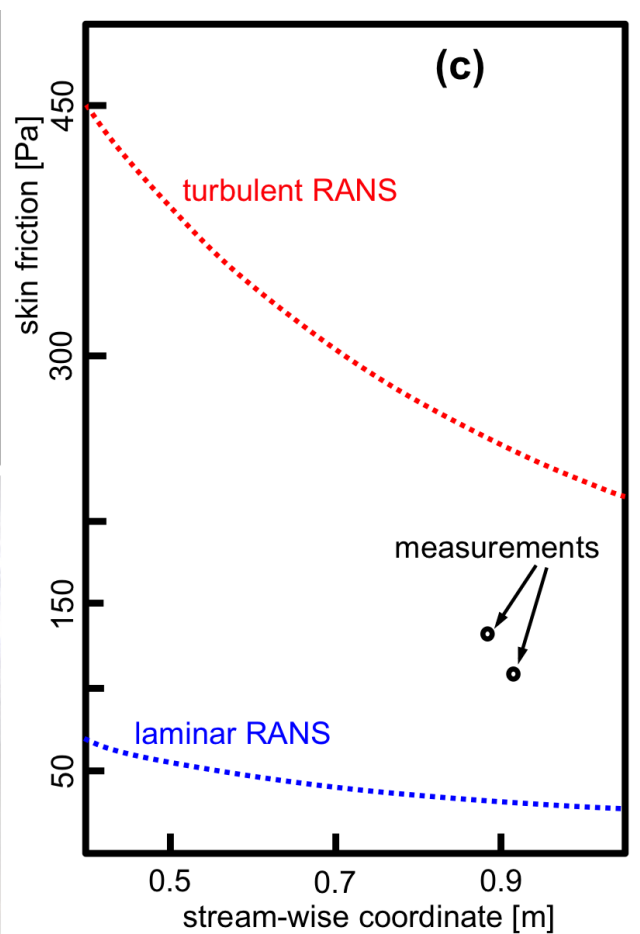

Figure 14: (a): oil dots on a checkered area for the reference image before a test (b): oil dots after a test (c): comparison among oil-dots skin friction measurements and CFD computations

to fifty four millions per meter. The shift from one Mach number to another during the qualification campaign resulted rather quick, and allowed as many as twelve tests per day.

The test unit Reynolds number can be regulated for a given Mach number varying the total temperature of the flow. This is possible acting on the initial pressure of the air in the compression process that builds up the total pressure of the flow. In so doing, the unit Reynolds number can theoretically vary from about forty millions to seventeen millions per meter at the lowest Mach number tested, and from fifty four millions to twenty millions per meter at the highest Mach number tested.

Also the test time can be selected for given total properties by varying the wind tunnel throat height as to reduce the mass flow through the divergent for the same initial amount of air.

The effectiveness of the main facility noise-reduction feature, the suction slots, has been verified numerically and resulted satisfactory in view of the absence of recirculation bubbles around the suction slot tip. Furthermore, heat flux measurements from a recent test campaign have found the boundary layer along the instrumented section of the lower ramp laminar for both the lowest and the highest Mach numbers qualified. These results, among others, will be the subject of a dedicated paper.

Low freestream fluctuations are another important parameter for transition experiments, and they were measured by hot-wire at two Mach numbers. They were found high for the strict quiet-wind-tunnel standards, but in the same range as a normal, non-quiet one. However, it must be noted that the strict quietness requirements here mentioned are only needed for experiments in natural transition, i.e. when the laminar boundary layer becomes turbulent without any external trigger. In case of induced transition, instead, these requirements relax because the effect of the trigger is found larger than the effect of the facility noise on the transition process.

The array of sensors already successfully used in the facility allows pressure, velocity, and wall temperature measurements, and all of them can be steady and/or unsteady. Furthermore, the use of Pressure Sensitive Paint allows the mapping of pressure fields around test articles mounted on the lower ramp of the wind tunnel divergent. In addition, the two-side optical access onto the wind tunnel is optimized for Schlieren visualizations and has been exploited to develop an optical technique for skin friction measurement: the oil-dot technique. This has been tried to investigate the state of the boundary layer along the lower ramp constituting one part of the supersonic divergent of the wind tunnel here presented. 


\section{Acknowledgments}

This work was performed within the Long-Term Advanced Propulsion Concepts and Technologies II project investigating high-speed transport, LAPCAT II, coordinated by ESA-ESTEC, and supported by the EU within the 7th Framework Program, Theme 7 TRANSPORT, Contract No.: ACP7-GA-2008-211485. Further info on LAPCAT II are available at: http://www.esa.int/techresources/lapcat_II.

The authors would like to thank Dr. T. Yasa, Mr. P. Londers, and Mr. G. Bonfanti for the support in the measurement campaign, and Mr. Nuño Vinha for the support in the numerical computations.

\section{References}

[1] M. C. M. Wright, P. A. Nelson, Wind tunnel experiments on the optimization of distributed suction for laminar flow control, Proceedings of the Institution of Mechanical Engineers, Part G: Journal of Aerospace Engineering 215 (6) (2001) 343-354. doi:10.1243/0954410011533347.

[2] M. C. M. Wright, P. A. Nelson, Fast boundary layer suction optimization with neural networks, Proceedings of the Institution of Mechanical Engineers, Part G: Journal of Aerospace Engineering 214 (2) (2000) 107113. doi:10.1243/0954410001531854.

[3] S. Schenider, Survey of boundary-layer transition for hypersonic applications, Short Training Course at the von Karman Institute for Fluid Dynamics (2011).

[4] F. Moens, J. Perraud, A. Sraudie, R. Houdeville, Transition measurement and prediction on a generic highlift swept wing, Proceedings of the Institution of Mechanical Engineers, Part G: Journal of Aerospace Engineering 220 (6) (2006) 589-603. doi:10.1243/09544100JAERO85.

[5] S. V. Murthy, F. W. Steinle, On boundary layer transition in high subsonic and transonic flow under the influence of acoustic disturbances and free-stream turbulence, in: AIAA 85-0082, 1985.

[6] S. R. Pate, Effects of wind tunnel disturbances on boundary-layer transition with emphasis on radiated noise: A review, in: 11th Aerodynamic Testing Conference, Colorado Springs, Colorado/March 18-20, 1980.

[7] W. Harvey, Influence of free-stream disturbances on boundary-layer transition, Tech. rep., NASA (1978).

[8] R. . Whalley, E. M., Optimum wind tunnel regulation, Proceedings of the Institution of Mechanical Engineers, Part G: Journal of Aerospace Engineering 215 (1) (2001) 241-252. doi:10.1243/0954410011533220.

[9] H. Naiman, D. D. Knight, S. P. Schneider, Computational redesign of the test section for the boeing/afosr mach 6 quiet tunnel, Proceedings of the Institution of Mechanical Engineers, Part G: Journal of Aerospace Engineering 223 (4) (2009) 407-413. doi:10.1243/09544100JAERO424.

[10] D. Arnal, Laminar-turbulent transition problems in supersonic and hypersonic flows, in: AGARD-R-761, 1988.

[11] B. Richards, Isentropic light piston facilities for simulation of hot flows through turbine, in: Advanced Testing Techniques in Turbomachines, von Karman Institute for Fluid Dynamics, 1978.

[12] D. Schultz, T. Jones, M. Oldfield, L. Daniels, A new transient cascade facility for the measurement of heat transfer rates, in: AGARD CP 229, 1997.

[13] S. P. Schneider, Numerical analysis of the bleed slot design of the purdue mach 6 wind tunnel, in: AIAA2005-91, 2005.

[14] N. Lin, H. Reed, W. Saric, Effect of leading edge geometry on boundary-layer receptivity to freestream sound, in: Stability, Transition and Turbulence, Springer-Verlag, New York, 1991.

[15] U. Goldberg, Subsonic and transonic external aerodynamics, in: CFD++ Capabilities and Verification, Metacomp Technologies, 2011. 
[16] S. R. Pate, Radiated aerodynamic noise effects on boundary-layer transition in supersonic and hypersonic wind tunnels, AIAA Journal 7 (1969) Nr. 3.

[17] E. Reshotko, Roughness-induced transition, transient growth in 3-d and supersonic flow, in: AVT 151 Lecture Series on Advances in laminar-turbulent transition modelling, RTO-AVT-VKI, 2008.

[18] P. A. Davidson, Turbulence, Oxford University Press, 2004.

[19] A. Pope, K. Goin, High-speed Wind Tunne Testing, R. E. Krieger Publishing Company, 1978.

[20] V. A. Lebiga, V. N. Zinoviev, Fluctuations characteristics of flows in test sections of high-speed wind tunnels, AGARD CP 58531 (1996) 1-9.

[21] A. Holden, The Nature of Solids, Columbia University Press, 1965.

[22] H. J. Gray, A. Isaacs, A New Dictionary of Physics, Longman GRoup Ltd., 1975.

[23] P. Schreivogel, G. Paniagua, H. Bottini, Pressure sensitive paint techniques for surface pressure measurements in supersonic flows, Experimental Thermal and Fluid Science 39 (2012) 189-197.

[24] L. Villafane, G. Paniagua, G. Bonfanti, T. Yasa, Enhanced video processing of oil streaks to measure skin friction, submitted to Sensors ISSN: 0954 (2014) -4100.

[25] L. C. Squire, The motion of a thin oil sheet under the steady boundary layer on a body, Journal of fluid Mechanics 11 (1961) 161-179.

[26] L. B. L. H. Tanner, A study of the motion of oil films on surfaces in air flow, with application to measurement of skin friction, Journal of Physics E Scientific Instruments 9 (1975) 194-202. 